\title{
Homozygous ARHGDIA Gene Mutation in an 11-Month-Old Infant with Steroid-Resistant Nephrotic Syndrome
}

\author{
Aditya Narayan $^{1} \cdot$ Pediredla Karunakar $^{1} \cdot$ Sriram Krishnamurthy $^{1}{ }^{1} \cdot$ Bobbity Deepthi $^{1} \cdot$ Divakar Jose $^{1}$
}

Received: 26 July 2021 / Accepted: 12 November 2021/Published online: 21 January 2022

(c) Dr. K C Chaudhuri Foundation 2021

To the Editor: An 11-mo-old developmentally normal girl was referred for evaluation of anasarca for the preceding 3 mo. At presentation, she had periorbital, pedal edema, severe ascites, and vulval edema. The weight was $9.3 \mathrm{~kg}(-1.30$ $z)$, length $79 \mathrm{~cm}(-0.61 \mathrm{z})$, and head circumference $44 \mathrm{~cm}$ $(-0.66 z)$. She had stage 2 hypertension. Investigations showed hemoglobin $10.5 \mathrm{~g} / \mathrm{dL}$, leucocyte count $6.9 \times 10^{9} / \mathrm{L}$, platelet count $285 \times 10^{9} / \mathrm{L}$, blood urea $92 \mathrm{mg} / \mathrm{dL}$, and serum creatinine $3.25 \mathrm{mg} / \mathrm{dL}$. Hypoalbuminemia $(2.1 \mathrm{~g} / \mathrm{dL})$, hypercholesterolemia $(270 \mathrm{mg} / \mathrm{dL})$, and nephrotic-range proteinuria (Up:Uc 5.5) without microscopic hematuria were noted. Ophthalmological evaluation and other systemic examination were unremarkable. She was born at 38 wk gestation as the firstborn to Telugu-speaking third-degree consanguineous parents (birth-weight $2.5 \mathrm{~kg}$ ). Despite 8 wk of daily prednisolone, she had not attained remission.

We initiated peritoneal dialysis, but she remained anuric and eventually died $18 \mathrm{~d}$ later due to multiorgan failure. Renal biopsy could not be performed. Clinical exome sequencing revealed homozygous missense likely-pathogenic variation in exon 6 of ARHGDIA gene (chr17:g.79826865C $>$ G) resulting in amino acid substitution of arginine for glycine (p.Gly168Arg). Prenatal counseling was provided.

Infantile nephrotic syndrome (INS) from India has been characterized by NPHS1, NPHS2, LAMB2, WT1, or PLCE1 gene mutations [1,2]. ARHGDIA mutations have not been reported in two large Indian series [1, 2] on INS. ARHGDIA mutations in INS have been reported so far in Pakistani [3], Moroccan, and Ashkenazi Jewish communities [4]. These cases had infantile-onset; showed diffuse mesangial sclerosis on renal biopsy; and rapidly progressed to end-stage renal disease (ESRD) or died [3, 4]. ARHGDIA mutations cause Rho-GTPase activation, causing podocyte damage [3, 4]. Unlike some previous cases [4], our patient did not have intellectual disability. Our report of INS due to ARHGDIA gene mutation adds to existing spectrum of genetic mutations in INS from India.

\section{Declarations}

Informed Consent Written informed consent for publication of the child's clinical details was obtained from the parents.

Conflict of Interest None.

\section{References}

1. Sinha R, Vasudevan A, Agarwal I, et al. Congenital nephrotic syndrome in India in the current era: a multicenter case series. Nephron. 2020;144:21-9.

2. Joshi A, Sinha A, Sharma A, et al. Next-generation sequencing for congenital nephrotic syndrome: a multi-center cross-sectional study from India. Indian Pediatr. 2021;58:445-51.

3. Gupta IR, Baldwin C, Auguste D, et al. ARHGDIA: a novel gene implicated in nephrotic syndrome. J Med Genet. 2013;50:330-8.

4. Gee HY, Saisawat P, Ashraf S, et al. ARHGDIA mutations cause nephrotic syndrome via defective RHO GTPase signaling. J Clin Invest. 2013;123:3243-53.

Publisher's Note Springer Nature remains neutral with regard to jurisdictional claims in published maps and institutional affiliations.

Sriram Krishnamurthy

drsriramk@yahoo.com

1 Department of Pediatrics, Jawaharlal Institute

of Postgraduate Medical Education and Research (JIPMER),

Pondicherry 605006, India 